\title{
POTENSI PANCASILA SEBAGAI FALSAFAH DUNIA
}

\author{
Fathorrahman \\ Universitas Pamulang \\ email:dosen01040@unpam.ac.id
}

Paper Accepted: 25 Juni 2018 Paper Reviewed: 7-15 Juli 2018 Paper Edited: 17-24 Juli 2018 Paper Approved: 25 Juli 2018

\begin{abstract}
ABSTRAK
Pancasila sebagai pandangan dunia yang dilahirkan oleh para The Founding Fathers negara Republik Indonesia (NRI) sangat layak dikenalkan kepada seluruh dunia. Pancasila memiliki potensi sebagai pandangan dunia yang sifatnya universal sekaligus unik dan khas Indonesia. Dari sisi nilai yang terkandung didalamnya tersusun secara filosofis, historis sekaligus bersifat aksiomatik, yaitu Tuhan, Manusia, Persatuan, Permusyawaratan (demokrasi) dan keadilan sosial. Sebagai falsafah dan ideologi negara, Pancasila memenuhi persyaratan yang lengkap sebagai ideologi yang baik yakni aspek idealitas, aspek realitas, dan aspek fleksibilitas. Oleh karena itu dapat disimpulkan bahwa Pancasila memiliki potensi untuk menjadi ideologi atau falsafah oleh bangsa-bangsa didunia. Sejalan dengan itu dibutuhkan upaya yang sistematis, dan berkesinambungan untuk membawa dan memperkenalkan Pancasila ke seluruh dunia, baik melalui kajian akademik antar universitas di seluruh dunia, maupun melalui kegiatan implementasi Pancasila dalam fora-fora pertemuan internasional.
\end{abstract}

Kata Kunci: Pancasila, falsafah dunia, forum internasional, ideologi.

\section{PENDAHULUAN}

Pancasila sejatinya sudah dikenalkan dalam forum internasional oleh mendiang Presiden sekaligus Proklamator Republik Indonesia Soekarno pada saat pertama kali berkunjung ke Amerika Serikat. Sebagaimana dilaporkan harian The New York Time, 18 Mei 1956, Soekarno sebagai Presiden Republik Indonesia merasa perlu untuk mendekati Amerika Serikat sebagai salah satu kekuatan politik dunia disamping Uni Sovyet.

Momentum itu dilakukan Soekarno setelah Konferensi Asia-Afrika di Bandung 1955, untuk menjelaskan posisi politik Indonesia dalam kancah dunia yang sedang terjadi polarisasi yang sengit antara blok negara-negara demokrasi liberal pimpinan Amerika Serikat dan negara-negara komunis pimpinan Uni Sovyet.

Pada 15 Mei 1956 Soekarno berpidato dengan lantang dalam sidang gabungan Kongres Amerika Serikat (AS) yang terdiri atas Dewan Perwakilan Rakyat dan Senat AS. Saat itulah Soekarno melakukan usaha memperkenalkan pada dunia mengenai Pancasila. Saat itu
Soekarno mengatakan, "Immediately we had proclaimed our independence, we attached our preamble to our constitution, the Pancasila, the five guiding principles of our national life, perhaps you know already what our Pancasila is"'(liputan The New York Time, 18 Mei 1956).

Soekarno kemudian menjelaskan lebih lanjut apa sebenarnya yang dia maksud dengan Pancasila itu dengan berkata, "It gives us the five principle of our state. There are: 1 . Believed in God, 2. Nationalism, 3. Humanity, 4. Democracy, 5. Social Justice. The five principles are combined reflections of Indonesia's natural climate and the personality of its inhabitants".(liputan The New York Time, 18 Mei 1956).

Dalam usaha menjelaskan Pancasila ini, Soekarno dengan lihai memperkenalkan kepada dunia khususnya kepada para pemimpin dan rakyat Amerika Serikat bahwa dirinya bukanlah orang yang anti demokrasi, karena demokrasi sendiri adalah bagian dari Pancasila. Saat itu Soekarno menegaskan, "You are now reaping the fruits of your pioneering struggle, which we still busy sowing the seeds from which our future national life will spring. You achieved 
youe national and cultural prosperity based upon the principle of democrazy which is one of your political boasts today". (Naskah pidato lengkap Soekarno di depan Kongres dan Senat $A S$, pada kunjungan pertama ke AS $15 \mathrm{Mei}$ 1956, pasca Konferensi Asia Afrika di Bandung tahun 1955)

Pada kesempatan yang sama, Soekarno juga menegaskan mengenai Pancasila merupakan alat untuk membangun stabilitas dan kesejahteraan nasional bagi Indonesia. Mungkin karena Amerika merupakan negara demokrasi liberal Soekarno juga menegaskan bahwa Pancasila juga menganut prinsip demokrasi, sebab demokrasi juga terkandung dalam Pancasila yakni sila keempat, kerakyatan yang dipimpin oleh khikmah kebijaksanaan dalam permusyawaratan/perwakilan.

Menurut Soekarno, Pancasila sesungguhnya adalah intisari sari sejarah peradaban bangsa Indonesia yang sama sekali tidak terpisah dari peradaban dunia. Oleh karena itu Pancasila seharusya juga menjadi falsafah dunia. Artinya sejak awal-awal kemerdekaan, Soekarno sudah melakukan usaha-usaha agar Pancasila yang menajdi dasar negara Indonesia itu dikenal diseluruh dunia. Ada upaya internasionalisasi nilai-nilai Pancasila dalam pentas pergaulan dunia.

Namun sayangnya, masalah Pancasila ini tidak lagi menjadi subyek yang penting dalam perkembangan pergaulan antar bangsa di dunia di tengah semaraknya isu-isu kapitalisme, liberalism, pasar bebas, komunisme dan ideologi-ideologi turunan yang lain.

Untuk menegaskan bahwa posisi Pancasila itu berbeda dengan ideologi yang lain, Soekarno menegaskan bahwa lima sendi dasar itu tidaklah langsung berpangkal pada manifesto komunis ataupun Declaration of independence Amerika Serikat. Namun demikian Soekarno juga tidak menampik bahwa gagasan-gagasan dan cita-cita itu yang ada dalam manifesto komunis maupun demokrasi itu mungkin sudah ada sejak berabad-abad, dan telah terkandung dalam denyut kehidupan bangsa Indonesia.

Pancasila memiliki prinsip-prinsip yang universal karena sila-silanya memuat hal-hal yang mendasar yang dibutuhkan oleh seluruh bangsa di dunia ini. Dalam konteks ini Notonegoro dalam bukunya, "Beberapa Hal mengenai Falsafah Pancasila", halaman 39-40 menjelaskan, Pancasila sebagai kebenaran absolut yang berpusat pada konsep inti yaitu Inti-Isi-Mutlak yaitu konsep, "Tuhan, manusia, satu, rakyat, dan adil”.

Dalam pandangan Notonegoro
kesemuanya itu bersifat "self evident", benar- benar ada dalam kenyataan hidup bangsa Indonesia. Menurut penulis justru apa yang disebut 'self evident' itu bukan hanya bagi bangsa Indonesia, namun juga dimiliki dan diinginkan serta menjadi cita-cita dari seluruh bangsa di dunia. Hal itu menjadi mimpi seluruh umat manusia dibumi.

Semua manusia dibumi ini mengakui adanya kehadiran Tuhan yang monotheistic, adanya prinsip kemanusiaan yang dilandasi keadilan dan beradab, menghendaki adanya persatuan bangsa agar mudah menggapai citacita bersama. Nilai Pancasila akan pentingnya berunding, bernegosiasi dan bermusyarwarah atas segala urusan dalam pergaulan hidup di dunia juga merupakan dambaan seluruh bangsa.

Bukti kongkrit akan kesdaran hal itu adalah adanya lembaga-lembaga dunia seperti Perserikatan Bangsa-Bangsa, NATO, Pakta Warsawa, SEATO, ASEAN, Unesco, WHO, Masyarakat Ekonomi Eropa, dan lembagalembaga dunia yang lain. Semua itu dilakukan semata-mata untuk menyalurkan hasrat dan mimpi-mimpi bersama akan adanya keadilan sosial bagi seluruh warga dunia, yang oleh bangsa Indonesia dirumuskan dengan sila kelima dari Pancasila yakni, 'Keadilan Sosial Bagi seluruh Rakyat Indonesia”.

\section{Perumusan Masalah}

Sejak dikenalkan Bung Karno pada 1 Juni 1945, Pancasila mengalami banyak pengalaman dan benturan sejarah. Pancasila dalam perkembangannya kerapkali mengalami benturan dengan ideologi-ideologi yang lain yang dianut oleh sebagian warga bangsa Indonesia. Benturan tersebut bukanlah suatu perkara kecil dalam kaitannya dengan kelangsungan hidup berbangsa dan bernegara yang berasaskan Pancasila. Beberapa pengalaman sejarah yang traumatic bahkan sempat membahayakan eksistensi Pancasila sebagai ideologi nasional.

Beberapa peristiwa sejarah politik kemudian muncul akibat perbedaan tafsir atas nilai-nilai Pancasila dalam hubungannya dengan kehidupan berbangsa dan bernegara. Misalnya kasus Pemberontakan G30 S/PKI yang secara nyata berupaya untuk mengganti ideologi Pancasila dengan ideologi komunisme.

Menurut Pakar Politik Salim Said dijelaskan bahwa peristiwa G30 S/PKI sesungguhnya terjadi karena pertikaian para elite PKI, Aidit Cs dengan para petinggi Angkatan Darat yang berselisih memperebutkan pengaruh Bung Karno yang sedang sakit. (Salim Haji Said; 2015). 
Pemberontakan PKI tersebut adalah upaya terakhir setelah peristiwa Madiun dalam usaha merongrong eksistensi Pancasila sebagai ideologi nasional Indonesia. Iklim dunia yang sedang mengalami polarisasi antara blok komunis dan blok liberal itu juga menjadi batu ujian bagi Pancasila dalam perjalanan sejarahnya. Peristiwa itu sengaja penulis jadikan ancaman seriuspada eksistensi Pancasila karena tujuan utamanya memang ingin mengganti ideologi Pancsila dengan komunis.

Faktanya Pancasila hingga saat ini masih tetap eksis sebagai ideologi dan falsafah negara Indonesia. Hal ini karena Pancasila merupakan pandangan hidup bangsa Indonesia, yang diyakini keberadaannya dalam kehidupan mereka. Pertanyaannya adalah, mengapa Pancasila hingga saat ini belum menjadi ideologi dunia sebagaimana kapitalisme, liberalisme, atau demokrasi, yang kemudian menjadi rujukan bangsa-bangsa lain dalam pergaulan internasional.

Bukankah Pancasila sebagaimana disebut dalam pendahuluan mengandung nilai-nilai yang universal dan dibutuhkan oleh seluruh bangsa didunia? Adakah upaya dari bangsa Indonesia untuk mensosialisasikan nilai-nilai dasar Pancasila itu dalam pergaulan internasional.

\section{METODE PENELITIAN}

Penelitian ini merupakan penelitian kualitatif dengan cara mengkaji sejumlah pandangan, pendapat-pendapat, teori-teori dari para ahli dalam berbagai literatur yang relevan untuk menemukan informasi-informasi yang berguna sebagai rujukan analisis. Penelitian ini diarahkan pada usaha-usaha mencari jawaban atas sejumlah dugaan dan premis-premis yang ada sebelumnya.

Penelitian ini menjadikan para pendapat ahli sebagai kerangka dasar pemikiran, untuk kemudian mendialogkannya dengan realitas yang baru. Peneliti berusaha menganalisa dan menemukan pikiran-pikiran baru tentang berbagai potensi yang terkandung dalam Pancasila terutama nilai-nilai substantifnya.

Nilai-nilai substantif Pancasila sejatinya merupakan nilai-nilai yang sifatnya universal sehingga dapat diasumsikan bahwa nilai-nilai tersebut dibutuhkan oleh setiap manusia di dunia ini.

\section{PEMBAHASAN}

\section{Menelisik Nilai Substantif Pancasila}

Pancasila adalah anugerah yang luar biasa sebagai karya falsafah bangsa yang khas digali dan dirumuskan secara par-excellence oleh para pendiri bangsa (the founding fathers). Profesor Dr. Notonegoro sampai pada kesimpulan bahwa Pancasila itu bersifat final and absolute truth.(Notonegoro $(1957 ; 26)$.

Berikut ini adalah kutipan lengkap sebagaimana dibawah ini:

"Pembukaan Undang-Undang Dasar 1945 sebagai Pernyataan Kemerdekaan yang terperinci yang mengandung cita-cita luhur dari Proklamasi Kemerdekaan 17 Agustus dan memuat Pancasila sebagai Dasar Negara, merupakan satu rangkaian dengan Proklamasi Kemerdekaan 17 Agustus 1945, dan oleh karena itu tidak dapat diubah oleh siapapun juga, termasuk MPR hasil Pemilihian Umum, yang berdasarkan pasa 3 dan pasal 37 UndangUndang Dasar berwenang menentapkan dan mengubah Undang-Undang Dasar, karena mengubah isi Pembukaan berarti pembubaran Negara"

Notonegoro selaku ahli mengenai Pancasila berpandangan bahwa Pancasila sebagai kebenaran absolut itu menghablur dalam paham organicisme, organic notion of state. Bahkan menyatunya Pancasila sebagai istilah itu, Notonegoro tidak membenarkan dua suku kata dari Panca dan sila itu ditulis Panca dan Sila, tetapi harus ditulis menyatu menjadi Pancasila.

Mari kita simak bagaimana seorang Notonegoro menguraikan Pancasila dari sila-sila yang sesungguhnya menjadi satu kesatuan itu. Pancasila menurut Notonegoro merupakan satu rangkaian kesatuan yang tidak bias dipisahkan satu dengan yang lain. Satu sila Pancasila, lanjut Notonegoro mengandung empat sila-sila lainnya. Betapa hebatnya nilai-nilai dalam Pancasila itu dalam pandangan Notonegoro.

Misalnya pada sila pertama, Ketuhanan Yang Maha Esa adalah ke-Tuhanan yang berkemanusiaan yang adil dan beradab, yang berpersatuan Indonesia, yang berkerakyatan yang dipimpin oleh khikmah kebijaksanaan dalam permusyawaratan/perwakilan, yang berkeadilan sosial bagi seluruh rakyat Indonesia. Saat menjelaskan mengenai kesatuan nilai diantara sila-sila dalam Pancasila itu, Notonegoro juga membuat teoritisisasi tersendiri yang kemudian kita kenal dengan konsep Inti. Konsep inti itu berbasis pada formula: inti-isi-mutlak. Apakah itu, yakni "Tuhan, Manusia, Satu, Rakyat, dan Adil" 
Menurut pemahaman Notonegoro, semua itu adalah suatu kenyataan yang ada dan hadir dalam kehidupan masyarakat bangsa Indonesia. Oleh karena itu semua itu tidak membutuhkan pembuktian soal ada atau tidak adanya.

Terkait dengan nilai-nilai Pancasila yang sering dikatakan sebagai tumbuh dan berada dalam bangsa Indonesia selama ribuan tahun dalam masyarakat Indonesia, ada baiknya kita melihat pandangan pemikir senior, Daniel Dhakidae. Menurut Daniel Dhakidae, pandangan tersebut tidak memiliki referensi yang jelas. Pancasila bukan turun dari dari langit karena sejak awal Pancasila dalam pengamatan Daniel dinilai telah menjadi medan pertempuran kekuasaan (the field of power).

Daniel memberikan alasan soal itu karena Pamcasila sejak dirumuskan didalam badan persiapan kemerdekaan telah menjadi pertandingan diskursus antara kalangan nasionalis dan kalangan Islam. Perang diskursus itu juga diyakini terjadi diantara kalangan Islam dan Islam lainnya atau jjga diantara kalangan nasionalis dan kalangan nasionalis lainnya.(FN:Baca, Daniel Dhakidae, Lima Bulan Yang Mengguncang Dunia, Pancasila, Proklamasi, dan Pendirian Negara Bangsa, majalah Prisma, Volume 37 No.2, tahun 2018).

Menurut penulis, Daniel Dhakidae benar, karena dalam banyak literature diseputar perumusan Pancasila, memang terjadi pertarungan ideologis yang sangat tajam antara kalangan muslim dengan kalangan nasionalis. Kalangan muslim berkeinginan agar dasar negara Indonesia yang akan dibangun berdasar Islam yang dinilainya mengandung ajaran kehidupan yang lengkap karena berasal dari Allah SWT. Namun kalangan nasionalis melihat fakta bahwa realitas bangsa tidak sepenuhnya beragama Islam atau muslim. Oleh karena itu, fakta sejarah soal munculnya dokumen yang kita kenal dengan Piagam Jakarta itu adalah logika pembenar apa yang disampaikan oleh Daniel Dhakidae.

Lalu, jika saja nilai-nilai luhur Pancasila itu bukanlah tumbuh dari nilai-nilai luhur bangsa Indonesia selama ribuan tahun, dari mana nilainilai itu datang? Pertanyaan ini sangat penting dikemukakan agar nilai-nilai Pancasila tersebut menjadi relevan jika kita kumandangkan sebagai nilai-nilai universal. Mungkin saja beberapa nilai luhur Pancasila tersebut menyatu dengan nilai dasar manusia sebagai makhluk ciptaan Tuhan. Namun pada saat yang sama kenapa juga muncul istilah-istilah yang dekat dengan istilah-istilah yang dikenal luas dalam dunia Islam.
Misalnya konsep dari istilah "permusyawaratan" atau istilah "keadilan", dari mana istilah itu datang? Bukankah kedua kata itu berasal dari Bahasa Arab yang tentu saja berkonotasi dengan Islam. Juga beberapa istilah yang terdapat dalam Pembukaan (preamble) Undang-Undang Dasar 1945. Misalnya frasa, "atas berkat Rahmat Allah", dan seterusnya. Adakah ini nilai-nilai Arabisme yang kemudian masuk ke alam pikiran para perumus Pancasila itu? Mengenai hal ini sebaiknya ada kajian tersendiri yang lebih komprehensif.

Pancasila sebagai nilai memiliki keunggulan yang sangat kompetitif jika disandingkan dengan ideologi besar dunia seperti Komunisme yang bangkrut bersamaan proyek Glassnot dan Perestroika dari Mochael Gorbachev. Begitu pula jika kita komparasikan dengan ideologi lain seperti Marxisme, Kapitalisme, maupun Liberalisme. Pancasila kalau dilihat dari spectrum ideologi-ideologi besar di dunia dapat diletakkan berada dalam posisi ditengah-tengah. Dalam konteks posisi ideologis Pancasila itu, cendekiawan muslim Nurcholis Madjid menyebut Pancasila itu sebagai "kalimatun sawa" sebuah ide moderasi yang mampu menghimpun berbagai aliran ideologis dunia. Oleh karena itu Pancasila, karena posisinya yang demikian itu mampu menjadi ideologi yang terbuka terhadap kemajuan dan perubahan baru yang datang. Dengan demikian Pancasila bias dikatakan sebagai idelogi yang terbuka. Keterbukaan itu membawa konsekuensi tersendiri karena Pancasila memiliki dimensi fleksibilitas yang menjadi prasyarat sebagai ideology yang baik dan mampu menghadapi tantangan zaman. (Nurcholis Madjid; 1996).

\section{Pengalaman Pancasila Sebagai Ideologi}

Kembali pada nilai substantif Pancasila sebagai satu kesatuan yang tidak bisa dipisahkan satu sama lain sebagaimana pendapat Notonegoro terdahulu, adalah juga penting melihat Pancasila itu dari sisi eksistensinya secara ideologis. Pakar filsafat Rocky Gerung misalnya melihat Pancasila itu sebagai sebuah ide penuntun, dan bukan pengatur. (Rocky Gerung, 2018, majalah Prisma, 37 (2).

Menurut Rocky Gerung, pada masa lalu, Pancasila diselenggarakan dengan cara memurnikannya, dan kita tahu bahwa itu adalah bagian dari politik otoritarian Orde Baru. Istilah "pemurnian Pancasila" menurut Rocky adalah proyek ideologi orde Baru melalui penataran 
Pedoman Penghayatan dan Pengamalan Pancasila (P4) yang bersifat indoktrinatif. Pancasila dalam pandangan Rocky adalah indoktrinasi baru dari orde baru menggantikan indoktrinasi Orde Lama yang juga menjadikan Pancasila sebagai jimat politik.

Di masa Soekarno, Pancasila lebih banyak dimanfaatkan sebagai upaya mensejajarkan Pancasila dengan ideologi Soekarnoisme yang berakhir dengan pengkultusan Soekarno oleh para pendukungnya. Sedangkan dimasa Soeharto, Pancasila diperlakukan sebagai alat pemurnian terhadap pemahaman orde lama yang revolusioner dan mengkerdilkan Pancasila sebagai alat penekan dengan menjadikan P4 sebagai penuntun setiap warga negara agar ideologi developmentalisme Soeharto berjalan dengan baik. (Rocky dalam Louis Althusser; 2014).

Titik kulminasinya, lanjut Rocky, Soeharto telah menjadikan Pancasila sebagai asas tunggal bagi setiap partai politik dan organisasi kemasyarakatan. Disinilah Rocky dengan analisanya yang kritis berkesimpulan bahwa kondisi Pancasila sebagai ideologi negara terpuruk diruang publik karena berhenti sebagai alat indoktrinasi untuk membungkam suara kritis (kritik), mematikan oposisi, dan melanjutkan kekuasaannya.

Pandangan Rocky ini benar dilihat dari bagaimana Pancasila dimanipulasi sedemikian rupa untuk menjadi jimat politik itu tadi untuk kemudian melanggengkan kekuasaan; apakah itu kekuasaan dimasa Orde Lama dibawah bayang-bayang Sukarno atau di masa Orde Baru dibawah kendali Soeharto yang dikenal sebagai rezim yang totalitarian. Dibawah Soeharto, Pancasila ditafsirkan secara tertutup melalui Badan khusus yang day to day memantau dan melaksanakan kegiatan indoktrinasi melalui penataran P4 (Pedoman Penghayatan dan Pangamalan Pancasila).

Upaya memperkenalkan Pancasila dengan pemahaman terbatas tersebut membawa situasi ketakutan dalam masyarakat, yang pada gilirannya membuat masyarakat menjadi apatis disatu sisi, sementara di sisi pemerintah/penguasa kehilangan kesempatan untuk mempromosikan falsafah dan ideologi Pancasila itu ke pentas dunia. Pemerintah Orde Baru tidak peduli pada usaha membawa dan memperkenalkan nilai-nilai Pancasila secara apa adanya sebagai suatu falsafah dan Dasar Negara Republik Indonesia dalam pergaulan antar bangsa.

Pancasila sebagai ideologi tunggal dan satu-satunya asas bagi organisasi social politik dan organisasi kemasyarakatan (Ormas) telah memasung kreatifitas masyarakat untuk berkreasi menggunakan nalar sendiri. Kondisi tersebut oleh Profesor Mas Achmad Icksan sebagai telah mendorong pada terbentuknya masyarakat yang berdimensi tunggal (one dimentional Culture) yang ditandai dengan lemahnya inisiatif dan kreatifitas bangsa. (Mas Ahmad Icksan, 1996).

Tradisi menjadikan Pancasila sebagai alat kekuasaan ini hingga saat ini sesungguhnya masih terjadi dan cenderung mempersempit kemungkinan munculnya tafsir yang berbeda dengan tafsir yang dirumuskan oleh pemerintah. Ada upaya penyeragaman pandangan terkait berbagai fenomena sosial politik dan kemasayarakat yang seringkali muncul secara tiba-tiba.

Saat ini, dimasa reformasi, dimana kebebasan dan kecerdasan masyarakat telah bergerak sangat cepat, pemerintah saat ini berusaha membuat badan khusus untuk mengembangkan Pancasila dalam praktik kehidupan bermasyarakat, berbangsa dan bernegara. Hal ini ditandai dengan dibentuknya Badan Khusus yang bertugas memasyarakatkan kembali nilai $=$ nilai Pancasila dalam masyarakat Indonesia.

\section{Memenuhi Prasyarat Ideologi Yang Baik}

Pancasila sebagai falsafah bangsa, ideologi negara, pandangan hidup (weltanchaung), dan dasar negara Republik Indonesia itu memiliki sejumlah dimensi dan keunggulan dibanding ideologi-ideologi lain yang ada di dunia. Sebagai suatu ideologi, Pancasila memiliki dan memenuhi prasyarat sebagi ideology yang baik, ideologi yang mampu menghadapi perubahan dunia yang bergerak sangat dinamis.

Disamping nilai - nilai yang terkandung dalam Pancasila, kita juga bisa meneropong Pancasila sebagai ideologi dari dimensi dimensi yang diperlukan sebagai syarat ideology yang baik. Secara teoritis, Pancasila memenuhi tiga dimensi ideologi yang baik.

Pertama, dimensi realitas. Dimensi realita atau dimensi realitas adalah bagaimana kita bisa menyadari bahwa pancasila adalah ideologi yang telah berada di tengah realita masyarakat. Hal itu tentunya berhubungan erat dengan nilai praktis Pancasila sebagai ideologi.

Kedua, dimensi fleksibilitas. Dimensi fleksibilitas ini mencerminkan Pancasila sebagai ideologi yang mampu mempengaruhi dan menyesuaikan dengan perkembangan masyarakat. Jadi, ideologi Pancasila bukan hanya sudah berada di masyarakat, tapi juga 
ikut berkembang seiring dengan perkembangan yang ada di masyarakat.

Ketiga, dimensi idealitas. Sudah wajar apabila sebuah ideologi haruslah mempunyai idealisme. Sama halnya dengan Pancasila yang mempunyai idealisme untuk mewujudkan negara yang sesuai dengan nilai - nilai Pancasila. Dimensi idealitas ini juga mencerminkan Pancasila yang mampu membakar semangat rakyat untuk terus mempunyai cita-cita, menjunjung tinggi dan mengamalkan Pancasila sebagai suatu gagasan bangsa yang ideal.

Dengan demikian maka Pancasila sebagai ideologi nasional nilai-nilainya mampu beradaptasi dengan perubahan apapun. Hal ini penting disadari, agar seluruh anak-anak bangsa memiliki rasa percaya diri yang tinggi dalam menatap masa depan dan bergaul secara bebas dalam pentas dunia yang terus berubah tanpa keraguan sedikitpun.

Dengan menyadari itu semua, sejatinya Pancasila dapat dikenalkan kepada seluruh bangsa-bangsa di dunia, agar mereka dapat memahami ideologi Pancasila itu secara baik, syukur alhamdulillah mereka dapat menyerap idealitas Pancasila secara nilai-nilai, apalagi mereka bersedia menerapkan nilai-nilai dasar Pancasila itu dalam kehidupan mereka. Artinya Pancasila memeiliki potensi untuk menjadi ideologi yang dapat dipahami dan dianut oleh seluruh manusia di dunia. Yang kemudian menjadi tantangan bagi bangsa Indonesia, khususnya para pemangku kekuasaan dan seluruh stake holder bangsa ini dalam upaya mensosialisasikan Pancasila secara kreatif ditengah perubahan dunia yang penuh ketidakpastian.

\section{Mendorong Pancasila Sebagai Falsafah Dunia}

Langkah pengenalan Pancasila dipentas dunia sudah dilakukan pertama kali oleh Presiden Sukarno dalam sidang Kongres dan Senat Amerika Serikat pada 1956. Langkah itu tentu merupakan langkah yang sangat penting sekaligus strategis bagi usaha memberikan pengenalan sekaligus pengertian masyarakat Amerika Serikat dan dunia internasional.

Praktik politik luar negeri Indonesia yang bersifat bebas aktif membuat Indonesia tidak berpihak negara-negara besar merupakan identitas dan falsafah dari Pancasila. Nilai-nilai ini juga pernah diperkenalkan Soekarno pada setiap kesempatan berbicara di depan forum Perserikatan Bangsa-Bangsa. Namun, sebagaimana diakui seorang diplomat senior, Makarim Wibisono, saat ini telah terjadi pergeseran karakter politikinternasional bersamaan dengan munculnya isu global baru, semacam perubahaniklim, good governance,hak-hak asasi manusia,dan demokrasi. (Makarim Wibisono, 2018, Prisma, 37 (2).

Semakin meluasnya konflik bersenjata mengalami perubahan pola menjadiintra-states conflicts, meningkatkan intensitas konflik di pentas global. Makarim memandang bahwa tidak tanggapnya PBB terhadap perkembangan konflik diberbagai belahan dunia, mengesankanbahwa PBB tidak berdaya menghadapi kejadian yang membahayakan perdamaian dan keamanan internasional. Selaku diplomat, ia merasakan akan pentingnya negara dalam hal ini Indonedia dapat ikut aktif berperan dalam situasi ekonomi-politik internasional yang tidak menguntungkan manusia didunia tersebut.

Indonesia sesungguhnya memilik potensi yang besar untuk tampil sebagai negara yangmmeimpin dunia, sebagaimana yang pernah ditunjukkan Soekarno di masa lalu. Beberapa pengalaman masa lalu Indonesia misalnya pernah menjadi pemimpin negaranegara non-blok, pemimpin konferensi AsiaAfrika tahun 1955 ditengah berkecamuknya perang dingin antara Amerika serikat dan sekutunya dengan Uni Sovyet.

Beberapa pernyataan Soekarno saat itu sedang memperlihatkan kelas kepemimpinannya dalam pentas internasional. Presiden Soekarno tidak segan-segan menandaskan bahwa Pancasila itu tidak hanya untuk lingkup nasional saja, tetapi juga cocok dalam lingkup global atau dunia internasional.

Soekarno percaya betul bahwa Pancasila mengandung lebih banyak daripada arti nasional saja, namun Pancasila mempunyai arti universal. Indonesia sebagai bangsa yang baru merdeka, lanjut Soekarno khawatir sistem perang dingin akan mengantarkan masyarakat internasional ke ketidakseimbangan global yang akan merugikan semua pihak.

Bahkan, Presiden Soekarno saat itu menegaskan dan berkata lantang, "Kami Bangsa Indonesia tidak bersedia bertopang dagu,sedangkan dunia menuju ke jurang keruntuhannya.Kami tidak bersedia bahwa fajar cerah dari kemerdekaan kami diliputi oleh awan radio aktif. Tidak satu pun diantara bangsabangsa Asia dan Afrika akan bersedia menerima hal itu. Kami memikul pertanggungan-jawab terhadap dunia,dan kami siap menerima serta memenuhi pertanggunganjawab itu". 
Dalam kaitan usaha mendorong Pancasila kepada pemahaman dunia akan nilai-nilainya yang dibutuhkan semua bangsa, Indonesia membutuhkan para pemasar (marketer) ideologi dan falsafah Pancasila kepada warga dunia. Untuk itu peran politik internasional Indonesia harus lebih ditingkatkan lagi agar mampu meningkatkan perannya dalam menciptakan ketertiban dunia yang penuh perdamaian.

Pengalaman menunjukkan bahwa keanggotaan di Dk-PBB telah mengangkat prestise dan derajat negara bersangkutan serta meningkatkan daya tawar dalam masalahmasalah percaturan politik global. Bila indonesia terpilih dalam acara pemilihan anggota dewan keamanan PBB di Majelis Umum PBB Juni 2018 yang bersaing dengan Maldives, yang mewakili Asia, maka mulai 1 Januari 2019 sampai dengan 31 Desember 2020.

Indonesia akan dapat menjalankan amanah Konstitusional secara langsung sebagai anggota DK-PBB untuk masa 2 tahun. Indonesia diyakini akan lebih berpengaruh dalam proses reformasi PBB secara keseluruhan: Indonesia akan memetik efek berantai dari keanggotaannya di DK-PBB.

Indonesia dapat menjadikan Sila pertama Ketuhanan Yang Maha Esa untuk meredakan konflik menyangkut agama, misalnya, antara Arab Saudi dengan Yaman. Sila kedua, kemanusiaan yang adil dan beradab dapat dipergunakan untuk mencegah kesewenangwenangan dan menghargai hak-hak nasional sebagai bangsa berdaulat. Sila ketiga yakni persatuan Indonesia dapat membawa inspirasi untuk mencegah pelanggaran hak asasi manusia dan kemanusiaan. Sila keempat dapat menciptakan kondisi terbentuknya lingkungan kondusif bagi proses pengambilan keputusan yang demokratis.

Sedangkan Sila kelima yakni keadilan social bagi selruh rakyat Indonesia dapat menjembatani kesenjangan yang ada di dunia. Apakah itu kesenjangan ekonomi, kesenjangan informasi antara negara yang pemilik jejaring digital serta komunikasi canggih dengan negara yang terbelakang di bidang informasi dan komunikasi. Juga dapat mengatasi kesenjangan antara negara maju dengan negara terbelakang di bidang ilmu pengetahuan dan teknologi. Pancasila sangta berpotensi untuk memberikan sumbangan berupa spirit baru yang mampu merevitalisasi lembaga perserikatan bangsabangsa guna mempersatukan keberagaman (pluralism).

\section{KESIMPULAN}

Untuk mengenang jasa-jasa besar para pendiri bangsa Indonesia, sudah sepantasnya kita sebagai bangsa yang besar menengok dan merumuskan kembali strategi yang tepat untuk menempatkan Pancasila sebagaimana layaknya sebuah falsafah atau ideologi negara kita. Pancasila tidak bisa lagi dimanipulasi nilainilainya semata untuk kepentingan politik jangka pendek oleh rezim politik tertentu. Pancasila harus dihidupkan nilai-nilainya dalam ranah yang lebih kongkrit untuk mendorong kemajuan bangsa dan negara Republik Indonesia.

Nilai-nilai substantive Pancasila yang oleh Profesor Notonegoro sebagai memiliki satu kesatuan yang utuh dan tidak bisa dipisahpisahkan, haruslah diimplementasikan secara nyata dilapangan,

Sesungguhnya

keterlambatan pembangunan nasional Indonesia, salah satu faktornya tidak mampu atau bahkan melupakan nilai-nilai dasar Pancasila dalam praktik kehidupan secara luas.

Pancasila secara teoritis memiliki dan memenuhi prasyarat-prasyarat yang baik sebagai ideology yakni dimensi idealitas, dimensi realitas, dan dimensi fleksibilitas. Dengan ketiga dimensi ideologis dalam Pancasila itu kita bias dengan percaya diri dapat memperkenalkan, menyebarkan ajaran-ajaran Pancasila itu ke dunia internasional. Semangat ini sejalan dengan tujuan konstitusional kita sebagaimana tertera dalam pembukaaan UUD 1945 yakni ikut serta dalam menciptakan perdamaian dunia dan keadilan sosial.

Semangat dan keinginan pemerintahan saat ini yang berusaha membangun Badan Pemantapan Ideologi Pancasila (BPIP) haruslah disambut baik, terutama dalam membumikan kembali nilia-nilai Pancasila ditengah perubahan yang cenderung mengarah pada suasana dan situasi ketidakpastian. Pemerintah dan seluruhanak bangsa hendaknya menyadari sepenuhnya agar tidak terjebak dalam praktik pemanfaatan Pancasila oleh kekuatan politik tertentu sebagaimana praktik pemanfaatan nilainilai Pancasila dimasa lalu. Hal itu akan sangat berbahaya bagi kemajuan bangsa.

Secara akademis diperlukan suatu kajian yang lebih komprehensif mengenai modelmodel sosialisasi Pancasila baik di level nasional maupun dunia internasional. Proses sosialisasi Pancasila adalah penting sekali dalam proses pendidikan politik bagi seluruh warga negara. Sejalan dengan itu, penting sekali agar pemerintah mampu menfasilitasi tumbuhnya 
semangat untuk meneliti tentang Pancasila dalam praktik kehidupan bernegara.

\section{DAFTAR PUSTAKA}

Althusser, Louis. (2014). Ideology and Ideological State Apparatus; London: verso.

Darmodihardjo, Dardji. (1978). Santiaji Pancasila, Lapasila, Malang.

Dhakidae, Daniel. (2018). "Lima Bulan Yang Mengguncang Dunia, Pancasila, Proklamasi, dan Pendirian Negara Bangsa". Prisma, 37 (2).

Gerung, Rocky. (2018). "Pancasila, Ide Penuntun, bukan Pengatur”. Prisma, 37 (2).

Icksan, Mas Ahmad. Naskah Pidato Wisuda Ketua Ikatan Keluarga Alumni IKIP Malang, 16 September 1996)
Madjid, Nurcholish. (1996). Pancasila sebagai Ideologi Terbuka, makalah Seminar Pancasila, Laboratorium Pancasila IKIP Malang.

Notonegoro. (1957). Beberapa Hal Mengenai Falsafah Pancasila Cet. 2, Pantjoran tujuh Jakarta.

Notonegoro. (1995). Beberapa Hal mengenai Falsafah Pancasila. Jakarta; Bumi Aksara.

Said, Salim Haji. (2015). Gestapu 65, PKI, Aidit, Sukarno, dan Soeharto. Bandung; Mizan.

Soekarno, naskah pidato lengkap Soekarno di depan Kongres dan Senat AS, pada kunjungan pertama ke AS 15 Mei 1956, pasca Konferensi Asia Afrika di Bandung tahun 1955).

Wibisono, Makarim. (2018). "Internasionalisasi Pancasila”, Prisma, 37 (2). 